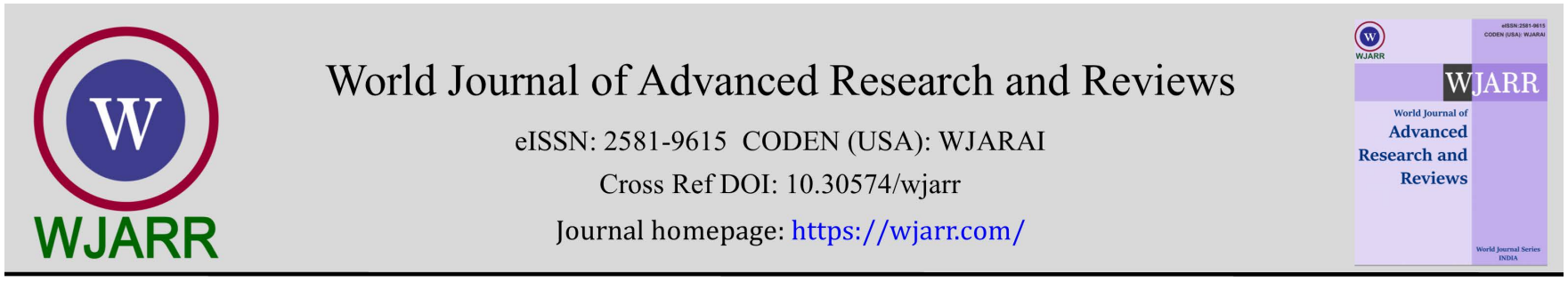

(RESEARCh ARTICLE)

Check for updates

\title{
First update course organized on a webinar by the West African College of Surgeons (Faculty of Radiology) during the COVID-19 pandemic and hosted by Ghana
}

Klenam Dzefi-Tettey 1, *, Emmanuel Kobina Mesi Edzie 2, Edmund Kwakye Brakohiapa 3, Franklin Acheampong ${ }^{4}$, Samson Seth Osei ${ }^{1}$, Kafui Kossi Kekessie 5, Henry Kusodzi ${ }^{2}$ and Abdul Raman Asemah ${ }^{2}$

${ }^{1}$ Department of Radiology. Korle Bu Teaching Hospital. 1 Guggisberg Avenue, Accra, Ghana.

2 Department of Medical Imaging, School of Medical Sciences, College of Health and Allied Sciences, University of Cape Coast, Cape Coast, Ghana.

${ }^{3}$ Department of Radiology, University of Ghana Medical School, Accra, Ghana.

${ }^{4}$ Korle Bu Teaching Hospital. 1 Guggisberg Avenue, Accra, Ghana.

${ }^{5}$ Department of Medical Imaging, University of Health and Allied Sciences, Ho, Ghana.

World Journal of Advanced Research and Reviews, 2021, 11(03), 371-381

Publication history: Received on 20 August; revised on 24 September 2021; accepted on 26 September 2021

Article DOI: https://doi.org/10.30574/wjarr.2021.11.3.0478

\begin{abstract}
Background: Teaching through virtual learning, such as webinars, has been found to be an effective medium in medical education, as well as many other professional training streams. The COVID-19 pandemic provided an opportunity to experiment with new teaching and learning methods by utilizing technology that allows for virtual online learning and education. Most scientific medical activities have shifted to online formats, in the form of webinars, to maintain continuing medical education. We aimed to assess the acceptance of webinar for delivering an update course in accordance with the Faculty of Radiology's curriculum.
\end{abstract}

Methods: This prospective study reviewed responses from 166 radiology resident trainees, who took part in an update course organized by the Faculty of Radiology of the West African College of Surgeons on 8th - 9th July 2020 via webinar. Participants were invited to respond to a 23-item questionnaire designed using Google Forms. Data obtained were analyzed with the aid of Statistical Package for Social Sciences (SPSS Inc. Chicago, version 20).

Results: From a total of 166 participants, males 88 (53.0\%) constituted the majority. Majority of the respondents $(95.2 \%)$ strongly agreed or agreed that the update course via webinar was really helpful and $(99.4 \%)$ of the respondents indicated that the update course has enhanced their knowledge on the topics presented. Almost all the participants $(94.6 \%)$ agreed to attend another update course on webinar, however, (5.4\%) of the participants suggest they prefer a face-to face update course over an update course via webinar.

Conclusion: Teaching in virtual mode (e.g. webinar) is a helpful technique for medical education, especially when social distancing is required. We found that the webinar was well-received and highly rated for educational objectives. Despite a few participants' stress and burden-related highlights, the majority of participants agreed that such a teaching mode would be beneficial.

Keywords: West African College of Surgeons; Radiology; Update Course; Webinar; Ghana; COVID-19.

\footnotetext{
* Corresponding author: Klenam Dzefi-Tettey

Department of Radiology. Korle Bu Teaching Hospital. 1 Guggisberg Avenue, Accra, Ghana.

Copyright $(2021$ Author(s) retain the copyright of this article. This article is published under the terms of the Creative Commons Attribution Liscense 4.0.
} 


\section{Introduction}

While the COVID-19 pandemic has interrupted medical education at all levels, it has had a particularly significant impact on medical education [1]. The Association of American Medical Colleges proposed the suspension of medical student clinical rotations on March 17, 2020, and has since maintained this position at the time this study was conducted. Preclinical programs have transitioned to a virtual format, in addition to the suspension of clinical rotations, to maintain social distancing of students [2].

The West African College of Surgeons (WACS), formerly the Association of Surgeons of West Africa, was founded in 1960 to develop alliance and better interaction among the first batch of West African surgeons who had completed their training abroad [3]. The college promotes, organizes, and conducts postgraduate education and training in surgery in West Africa. It is made up of eight surgical faculties: Anesthesia, Dental Surgery, Obstetrics \& Gynecology, Ophthalmology, Otorhinolaryngology, Radiology, Orthopedics and Surgery [4]. WACS is made up of almost 6,000 Fellows from eighteen West African countries in the eight surgical specialties [5]. The WACS's objective is vast, but at its heart is the training of surgical professionals to provide surgical services to the member countries [6]. The WACS has achieved substantial progress toward its goals in its 60 years of existence [7].

The Faculty of Radiology, under the umbrella of the WACS, is aimed at producing highly trained radiologists to provide quality radiological services to the highest standard throughout the sub-region [8]. The Faculty's goals are to enhance the science, art, and practice of radiology and related sciences, as well as to encourage radiology education, study, and research [9]. In addition to actual experience, the first year is devoted primarily to the study of radiological anatomy, radiological physics, radiological procedures, radiography, and theoretical subjects. The subsequent years are spent studying a radiology curriculum, which includes specialist sections, with regular faculty exams. External examiners assist in Fellowship examinations, which lead to the award of a postgraduate qualification of Fellowship of the Faculty of Radiologists of WACS [10]. The most exciting aspect of Radiology as a field is that it is constantly evolving and, as a result, residency training must keep pace. As part of its mandate, the Faculty of Radiology is obliged to organize a Continuous Professional Development (CPD) program through updates and review courses at least four times in a year [11] which rotates between Nigeria and Ghana. Resident trainees and facilitators travel to and from these two countries in order to attend these update courses.

Consistently, throughout the different generations of radiologists and surgeons, didactic lectures, apprenticeship, tutorials, and Continuous Professional Development (CPD) have been the only mode of education and medical training [12]. CPD is defined as the continuous improvement of one's knowledge, skills, attitudes, and behavior in all areas of professional activity. CPD, according to the Royal College of Radiologists (RCR), is a continuous process that includes any educational activity that aids in the enhancement of one's knowledge, problem-solving skills, technical skills, behavior, and professional standards of medical practice in order to improve the safety and quality of healthcare [13]. In line with the General Medical Council's CPD, doctors should participate in CPD activities that are relevant to their practice and support their professional development, such as attending high-quality face-to-face meetings, courses and events accredited by national professional bodies, and distance learning from appropriate online resources such as webinars and recorded lectures, according to the RCR CPD scheme $[13,14]$.

The ongoing COVID-19 pandemic has had rippling repercussions on the healthcare system, and as a result, medical education at all levels, from undergraduate to postgraduate, has been impacted [15]. Since the emergence of COVID-19, one of the most effective preventive strategies has been to prohibit students from congregating in learning studios, lecture halls, or small-group spaces [16]. In addition, the border closure of most countries including Ghana and Nigeria [17] at the time the update course was scheduled made it impossible for radiology residents and facilitators to travel. During times of crisis, medical educators should take advantage of technology for both undergraduate and postgraduate medical education. Higher education and professional training are increasingly using digital learning environments. One popular method for teaching and learning is through webinars and online conferencing in general [18]. While newer initiatives like webcasts are becoming more popular, in-person didactic lectures and tutorials are still an important part of medical education [19].

Despite the fact that webinar frequency and content have increased during this pandemic, there is a scarcity of evidence on how participants perceive and use webinars in such stressful circumstances. We used an internet-based crosssectional survey with questionnaire to learn about participants' impressions and characteristics of such webinars. Also, being the first update course of the WACS and hence the faculty to be organized on webinar, the present study aimed at evaluating the acceptance of update course in the form of a webinar for a continuous professional development. 


\section{Objectives}

- To compare the virtual experience with the physical meetings.

- To obtain views from the attendees in order to improve on future virtual update courses.

- To determine whether the virtual update course was effective.

- To determine the demographics, level of residency training and the jurisdiction of attendees.

\section{Material and methods}

An update course on pulmonary radiology and radiation oncology was organized by the Faculty of Radiology of the West African College of Surgeons with participants from different training centers in Ghana and Nigeria on $8^{\text {th }}$ and $9^{\text {th }}$ July 2020 on a webinar. Fourteen Radiology Faculty members, comprising members from Ghana and Nigeria, were each given a maximum of 60 minutes for their presentations. The content was planned according to the WACS Faculty of Radiology residency curriculum (Table 1). Registration and payment was online via the West African College of Surgeon's website. The lead author for this survey, who is also a Faculty member and facilitator, coordinated the webinar. Each presentation lasted for 40 minutes and an additional 20 minutes for questions and answers, and screen sharing. The webinar featured content experts for the selected topics and were delivered using an online meeting software platform (zoom). All presentations were made available on the web page of the college for registered members.

Table 1 Webinar overview

\begin{tabular}{|c|l|}
\hline Number of lectures & \multicolumn{1}{|c|}{ Topic } \\
\hline 1 & $\begin{array}{l}\text { Radiological anatomy of the lung and techniques of imaging the } \\
\text { lung. }\end{array}$ \\
\hline 2 & $\begin{array}{l}\text { Radiological anatomy of the mediastinum and techniques of } \\
\text { imaging / investigations }\end{array}$ \\
\hline 3 & Pulmonary infections including covid-19 \\
\hline 4 & $\begin{array}{l}\text { Anatomic approach and interpretation of high resolution chest CT } \\
\text { scan and pulmonary embolism }\end{array}$ \\
\hline 5 & Congenital lesions of the lung \\
\hline 6 & Radiology of mediastinal pathologies \\
\hline 7 & $\begin{array}{l}\text { Overview on the current indications for systemic therapy and } \\
\text { radiation therapy in lung cancer }\end{array}$ \\
\hline 8 & Malignant tumors of the lung \\
\hline 9 & $\begin{array}{l}\text { Benign tumors of the lung and radiology of occupational lung } \\
\text { diseases }\end{array}$ \\
\hline 10 & Chest trauma \\
\hline 11 & Diseases of the airways \\
\hline 12 & Pulmonary scintigraphy \\
\hline 13 & $\begin{array}{l}\text { Radiology of pulmonary edema (cardiogenic and non-cardiogenic) } \\
\text { pulmonary hypertension and congestive heart failure }\end{array}$ \\
\hline 14 & $\begin{array}{l}\text { Vascular and non-vascular interventional techniques / procedures } \\
\text { in the thorax }\end{array}$ \\
\hline & \\
\hline
\end{tabular}

Just after the end of the 14th lecture, all the registered radiology resident trainees (166 participants) were invited by email to complete an online survey about their experiences and opinions of the webinar after they had completed an informed consent form. Google Form was the online platform used to deliver the self-administered surveys. To complete the survey, users must be signed in to a Google account, which prevents duplicate responses from the same person. The e-mail addresses used were not collected in order to protect anonymity. A 23-item questionnaire was created, which included dichotomous, multiple-choice, Likert response scale, and open-ended questions. The survey captured: 
- Self-reported satisfaction from the update course/webinar.

- Knowledge acquired from participating in the update course.

- General opinion on the update course.

- Suggestions on making the next experience better.

In measuring their satisfactory level, participants were asked to rate the update course in terms of meeting their needs and expectations, overall quality of the update course and presentation skills of the facilitators. Responses were rated using a 4-point Likert scale from excellent (1) to poor (4). The participants' knowledge increase was measured on a dichotomous scale (yes or no) by asking respondents whether the update course/ webinar has enhanced their understanding of the topics. We solicited for their opinions with regards to how helpful the update course was, how knowledgeable the facilitators were in their respective subject area and what they think about the activities within the update course. In order to make the next experience better, we assessed what they like the most and the least about the update, suggestions on improvements and how they would want future update courses to be organized.

All open ended responses were captured under common themes, grouped and coded together with the close ended responses. The data obtained was analyzed and presented descriptively using frequencies and associated percentages with the aid of Statistical Package for Social Sciences (SPSS Inc. Chicago, version 20).

\section{Results}

A total of 166 radiology resident trainees attended the update course and all willingly participated in the study. They were from 25 different training institutional sites from Ghana and Nigeria. Characteristics of the sample are shown in (Table 2). Majority of the participants were males (53.0\%) with (47.0\%) being females. Junior residents (56.6\%) constituted majority. Overall, 25-35-year group represented the largest age group followed by 36-40-year old group (53.0\% and $33.7 \%$ respectively).

Table 2 Demographic characteristics of participants

\begin{tabular}{|c|c|c|}
\hline & Count & Percentage \\
\hline \multicolumn{3}{|l|}{ Gender } \\
\hline Male & 88 & 53.0 \\
\hline Female & 78 & 47.0 \\
\hline \multicolumn{3}{|l|}{ Age (years) } \\
\hline $25-35$ & 88 & 53.0 \\
\hline $36-40$ & 56 & 33.7 \\
\hline $41-45$ & 14 & 8.4 \\
\hline $46-50$ & 7 & 4.2 \\
\hline $51-55$ & 0 & 0.0 \\
\hline $56-60$ & 1 & 0.6 \\
\hline Above 60 & 0 & 0.0 \\
\hline \multicolumn{3}{|c|}{ Level of residency } \\
\hline Junior resident & 97 & 58.4 \\
\hline Senior resident & 69 & 41.6 \\
\hline \multicolumn{3}{|c|}{ Country of origin } \\
\hline Ghana & 26 & 15.7 \\
\hline Nigeria & 140 & 84.3 \\
\hline
\end{tabular}


Overall, the participants gave a positive ranking on how satisfied they were with the update course. Almost all the participants (99.4\%) stated that the update course in terms of quality, presentation skills of the facilitators, meeting their needs and expectations were either excellent or satisfactory (Table 3). Even though most participants (51.8\%) had issues with network interruptions, none of them indicated the workshop was poor (Table 3 \& Figure 2).

Table 3 Self-reported satisfaction of participants

\begin{tabular}{|l|c|c|c|}
\hline & Quality (\%) & Meeting expectations (\%) & Presentation skills (\%) \\
\hline Excellent & 44.6 & 31.3 & 41.0 \\
\hline Satisfactory & 54.8 & 67.5 & 58.4 \\
\hline Unsatisfactory & 0.6 & 1.2 & 0.6 \\
\hline Poor & 0.0 & 0.0 & 0.0 \\
\hline
\end{tabular}

Majority of the participants (32.5\%) indicated that, the convenient nature of the webinar by accessing the update course from the comfort of their homes, without traveling with its risks, and how well it was organized, were what they liked most about the update course (Figure 1). Whilst $4.8 \%$ of the participants did not like the associated cost with the webinar, $7.2 \%$ thought it was cost effective (Figure 1\& 2). A large number of participants felt that both the number of participants that signed up for the update course and duration of the update course were just the right number $(64.5 \%$ and $74.1 \%$ respectively) (Table 4 ).

Table 4 Views on participant's number and duration of update course

\begin{tabular}{|l|c|c|}
\hline & Number of participants (\%) & Duration of the update course (\%) \\
\hline Too long & N/A & 8.4 \\
\hline Too many & 1.8 & N/A \\
\hline Just about right & 64.5 & 74.1 \\
\hline Neutral & 33.7 & 12.0 \\
\hline Too short & N/A & 5.4 \\
\hline Too few & 0.0 & N/A \\
\hline
\end{tabular}

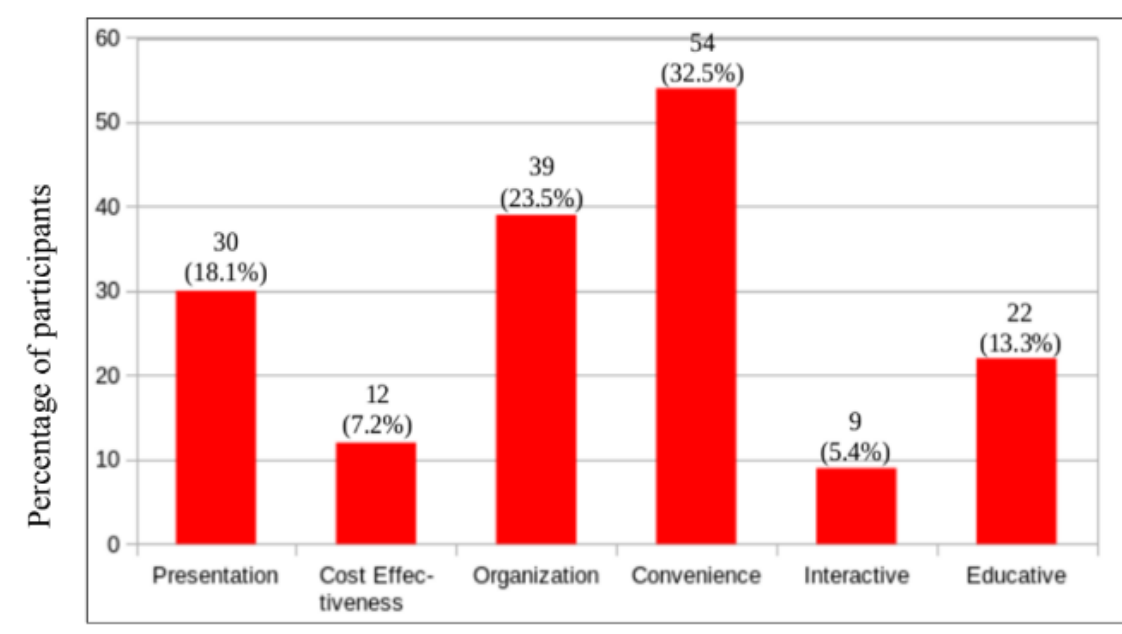

Participants' reasons for preferring update course via webinar

Figure 1 What you like most about the update course via webinar 




Participants' reasons for disliking update course via webinar

Figure 2 What you like least about the update course via webinar



Participants' suggestions to make their next experience better

Figure 3 Improvements you would suggest to make your next experience better

The respondents were further assessed using Likert scales with 1 to 5 items; 1 - strongly disagree to 5- strongly agree (Table 5). 50.0\% 'Strongly Agreed' and 41.0\% 'Agreed' that the registration process was easy and cost effective. With respect to the activities, 25.9\% 'Strongly Agreed' and 65.1\% 'Agreed' that the activities during the update course were appropriate and reasonable in the time allowed. When asked whether the update course was really helpful, the majority of the respondents 'Strongly Agreed' (52.4\%) or 'Agreed' (42.8\%) to this assertion. During the lecture, nearly all the participants (94.6\%) were particularly satisfied with how their questions were addressed during the Question \& Answer (Q\&A) sections. Owing to that, majority of the respondents either 'Strongly Agreed (56.0\%)' or 'Agreed' (39.8\%) that the facilitators were knowledgeable in their respective subject area (Table 5). To that effect, $99.4 \%$ of the participants have enhanced their knowledge as a result of participating in the update course. 
Table 5 Perceived value of activities of the update course/webinar

\begin{tabular}{|l|c|c|c|c|}
\hline & $\begin{array}{c}\text { Easy } \\
\text { Registration } \\
\text { Process (\%) }\end{array}$ & $\begin{array}{c}\text { Update course } \\
\text { was helpful (\%) }\end{array}$ & $\begin{array}{c}\text { Facilitators were } \\
\text { knowledgeable } \\
\text { (\%) }\end{array}$ & $\begin{array}{c}\text { Activities were } \\
\text { appropriate } \\
\text { (\%) }\end{array}$ \\
\hline Strongly agree & 50.0 & 52.4 & 56.0 & 25.9 \\
\hline Agree & 41.0 & 42.8 & 39.8 & 65.1 \\
\hline Neutral & 2.4 & 1.2 & 1.2 & 4.8 \\
\hline Disagree & 1.2 & 0 & 0 & 2.4 \\
\hline Strongly disagree & 5.4 & 3.6 & 3.0 & 1.8 \\
\hline
\end{tabular}

All participants agreed to attend another update course on webinar, however, $3.0 \%$ of the participants suggested their preference for a face-to face update course over an update course on a webinar. Whilst just a few (2.4\%) suggested other means for organizing future update courses, all but one was indifferent between choosing a webinar or a face-toface approach and one participant did not agree to recommend update course on webinar to colleagues either (Table 6).

Table 6 Participants assessment and recommendation of update course on webinar

\begin{tabular}{|l|c|c|}
\hline \multicolumn{2}{|c|}{ Count (\%) } & Percentage (\%) \\
\hline Questions answered to your satisfaction \\
\hline Yes & 157 & 94.6 \\
\hline No & 9 & 5.4 \\
\hline Knowledge increased & 165 & 99.4 \\
\hline Yes & 1 & 0.6 \\
\hline No & 157 & 94.6 \\
\hline How future update course should be organized \\
\hline Via webinar & 9 & 5.4 \\
\hline Face-to-face & 166 & 100.0 \\
\hline Attend another update course & 0 & 0.0 \\
\hline Yes & 165 & 99.4 \\
\hline No & 1 & 0.6 \\
\hline Recommend to colleagues & \\
\hline Yes & & \\
\hline No & & \\
\hline
\end{tabular}

\section{Discussion}

Due to the Covid-19 pandemic and the resulting restrictions on in-person student instruction, educators have had to quickly adapt to the "new normal" of remote online learning. The challenges of finding new approaches to engage learners and demonstrate the breadth of medical training presents chances to positively influence the future of medical education. In the wake of this pandemic, one of the primary goals of a course design is to simulate the clinical experience in a virtual environment [20]. 
Residents' feedback is an important tool for identifying program enhancement potential. Based on a virtual education platform, we conducted a poll of participants' perceptions on the update course. The findings were encouraging, highlighting the fact that webinars have a high success rate as a virtual learning platform during the pandemic, which had limited physical learning. In our study, $94.6 \%$ of the participants preferred subsequent update courses to be organized via webinars. Despite the network interruptions as reported by some participants, the decision to maintain webinar-based education delivery demonstrates that during the pandemic, webinars have become a source of virtual accessibility and adaptability for medical learning. Though frequent webinars may cause technical difficulties, stress, and additional burden, technological advancements and high-quality multifunctional modalities for online meetings have made this mode quite fruitful and praiseworthy, particularly in situations requiring social distancing, especially as webinars have been demonstrated to be a supplement to traditional classes for medical education [21]. However, other studies reported contrary findings, such as a study conducted in Saudi Arabia by Figueroa et al, the perception of neurosurgery residents on online webinars during the Covid-19 pandemic showed that the majority of the participants disagreed that webinars should replace face-to-face traditional workshops [22]. Moreover, 54.8\% of medical students in Libya disagreed that e-learning should be used for clinical instruction in the post-pandemic age, according to a research including 13 medical schools [23]. They argued that Problem-based learning (PBL) is a student-centered educational strategy in which groups of students guide themselves through distinct case-based scenarios while applying their medical knowledge and clinical reasoning skills. With virtual learning, these features are likely to be ineffective. The pandemic has taught institutions to look for positive and beneficial improvements to make learning easier and more comfortable for their audience. The findings of Figueroa et al and Ahmed Alsoufi et al [22, 23] emphasizes the significance of implementing a system that can adapt to the pandemic's virtual learning hurdles. A recent study of healthcare professionals found high satisfaction with a similar virtual workshop based model, which is backed by our findings, in which participants expressed high level of confidence and satisfaction [24]. In southern California, before the COVID-19 pandemic, Avila et al studied the acceptance and feasibility of a post-webinar training evaluation conducted via Survey Monkey. In their web-based abstractor training session at selected places, Avila et al. noted the great utility of webinars for delivering scientific knowledge and information [25].

During the Covid-19 pandemic, applications such as Zoom, Skype, Web X, Microsoft Teams, and Google Meet are being used as virtual platforms for lectures and teaching sessions. Overall, the participants from our study rated workshops via webinars to be cost effective and convenient. A recent meta-analysis of randomized controlled trials looked at the effectiveness of webinars as virtual learning platforms [26], and the results were comparable to what we found in our study. Nadama et al. conducted a study on webinar-based education among students in the United Kingdom [27]. Nearly half of those who responded to their survey had never attended a webinar before, and more than $90 \%$ felt that webinars offer great convenience and flexibility in terms of learning, location, and schedule. They discovered that webinars were an effective way to get the idea out to the audience. Webinars were found to be an effective and convenient method of teaching behavior therapy and coping flexibility to employees in the workplace [27]. In a qualitative study by Kimura et al., webinars were discovered to be the most effective and easy way of conveying information and developments across a wider geographical distribution [28]. Webinars were not only cost-effective, but also a platform that could be used by anyone for face-to-face engagement. This suggests that a useful online program for medical academics is on the way.

Because of their user-friendliness, online webinars are becoming increasingly popular as a learning platform [29]. The acceptance of virtual online learning via webinars and other methods has posed some challenges for medical education. Despite its benefits, webinars have been noted for limiting engagement [30]. Several participants from our study suggested an increased in time allotment to make room for interaction with the facilitators. The socializing barrier was identified as one of the most significant issue regarding the use of webinar from our study. Professional networking and collaboration may be lost as a result of the loss of face-to-face contact with peers, which was previously prevalent in conference attendance.

In a poll looking into the usefulness of webinars among medical students in Japan, it was discovered that webinars were quite valuable in supplementing participants' knowledge [31]. Since the advancement of technology, webinars have become a popular means of disseminating courses, lessons, instructions, and innovations around the world. Weston et al. found that online Continuing Medical Education (CME) in routine training provided significant benefits to physicians [32]. Gupta et al. conducted a cross-sectional online survey on healthcare online learning and found that online networks improve the quality of care provided to users and disseminate new ideas and viewpoints [33]. They stated that online classes and meetings are becoming a more convenient approach to stay up with continuing medical education, scientific knowledge, and medical competencies.

As seen by the number of articles on web-academics, the popularity of webinars has increased during the COVID-19 pandemic. Hari Prasetyono et al. found that webinars with a shorter duration had higher participation and better results [34]. According to Bell et al., more than $90 \%$ of dentists in their survey thought it was advantageous [35]. Compared to 
popular traditional methods, Patel et al. discovered that webinars are used less for various learning reasons [36]. Webinars during COVID-19, according to Serebrakian et al., helped medical residents boost their confidence and knowledge [37]. Our study looked at all possible benefits, drawbacks, and preferences of organizing an update course via webinar. We discovered similar outcomes as in the case of the studies presented above [34-37], such as enhanced webinar utility, convenient learning without the stress of traveling to the venue.

\section{Limitations}

This study was limited by the short duration of the webinar and the inherent limitations and biases of a survey study. Also, the lack of a control group limits the evaluation of the effectiveness of the webinar. Evaluation using a pre-testpost-test design was impractical because of limited preparation time. However, further research comparing video conferencing and traditional didactic instruction techniques could yield useful insights about how to improve virtual radiology education in the future.

\subsection{Implication for practice}

From the perspective of the radiology residents, our study has provided the evidence on the utilization and implication of webinars. This study has bolstered the notion that webinars can have more positive characteristics. Simultaneously, it has stressed the impediment posed by the proliferation of untimely and poorly prepared webinars on residents. This study could be a watershed moment in establishing the efficacy of webinars as professional residency training in both normal and disaster times. The COVID-19 pandemic has altered people's perspectives and way of life. Web-based education is the primary means of receiving updates and continuing education while maintaining social distancing at our own location. It has its own set of advantages and disadvantages. On this topic, we looked at the facts and opinions of radiology residents and other sub-medical specialty residents reviewed from literature. The findings of the study will keep all stakeholders (faculty members, policy makers, doctors, etc.) updated about the best approaches to improve output and web-hour productivity. This will assist event planners in properly planning upcoming webinars for themselves and their resident doctors.

\section{Conclusion}

In conclusion, the COVID-19 pandemic has not only disrupted the status quo, but it has also accelerated the adoption of virtual and experiential learning opportunities that none of us could have predicted. The majority of institutions have adopted technology as a means of preserving normalcy. In this period of social distancing, virtual meetings preserve specialized teaching conferences for both trainees and medical students, facilitate regular workstation feedback to residents, and bring the community together. We observed high appraisal and rating of webinar for learning purposes. Despite a few individuals' stress and burden-related highlights, the majority of participants were in favor of such a teaching module. For the lockdown period and beyond, webinars were shown to be an excellent replacement for traditional instruction

\section{Compliance with ethical standards}

\section{Acknowledgments}

We are thankful to all the radiology residents who gave consent and took part in this study.

\section{Disclosure of conflict of interest}

None to declare

\section{Statement of informed consent}

Written informed consent was obtained from each radiology residents prior to the administration of the questionnaires.

\section{Ethical Consideration}

Ethical consideration for this study was sought from the Institutional Review Board of the Korle Bu Teaching Hospital with clearance number KBTH-ADM/00354/2020 as confidentiality and anonymity was maintained throughout the study. 


\section{Authors' Contributions}

K. Dzefi-Tettey, E. K. M. Edzie, E. K. Brakohiapa, F. Acheampong, S. S. Osei, Kafui Kossi Kekessie, H. Kusodzi and A. R. Asemah made substantial contributions to conception, design, literature review, data acquisition and analysis, interpretation of the data, drafting, proof reading and approval of the manuscript for publication.

\section{References}

[1] Harries AJ, Lee C, Jones L, et al. Effects of the COVID-19 pandemic on medical students: a multicenter quantitative study. BMC Med Educ. 2021; 21: 14.

[2] Prescott JE. Important Guidance for Medical Students on Clinical Rotations During the Coronavirus (COVID-19) Outbreak. 2020.

[3] Ajayi 00, Quartey JKM, Adebonojo SA, (Eds.). Knife in Hand: The history of the West African College of the Surgeons (1960-2019) (Archampong, E.Q. 2nd ed.). Accra, Ghana: The West African College of Surgeon. 2019.

[4] The West African College of Surgeon. https://www.wacscoac.org/index.php/faculties Accessed 15 th June, 2020.

[5] Yawe, K.D.T. FWACS West African College of Surgeons and its role in global surgery. 2018. https://bulletin.facs.org/2018/05/west-african-college-of-surgeons-and-its-role-in-global-surgery/

[6] The West African College of Surgeon. https://www.wacscoac.org/index.php/about-us/college-objectives Accessed 20th June, 2020.

[7] Omigbodun A. The membership certification of the West African college of surgeons and its relevance to the needs of the West African sub-region. J West Afr Coll Surg. 2012; 2(3): 83-87.

[8] Faculty of radiology. https://www.wacscoac.org/index.php/faculties/radiology Accessed on 17th July, 2020.

[9] Ajao OG, Ugwu BT. A case against the membership programme proposal of the West African College of Surgeons. J West Afr Coll Surg. 2012; 2(3).

[10] Radiology Curriculum. Membership and fellowship programmes in clinical radiology. https://www.wacscoac.org/index.php/faculties/radiology.

[11] Continuing Professional Development National Guidelines. Accessed on 17th July, 2020.

[12] Bode CO, Olatosi J, Amposah G, Desalu I. Has the middle-level anaesthesia manpower training program of the West African College of Surgeons fulfilled its objectives? Anaesth Intensive Care. 2013; 41(3): 359-362.

[13] The Royal College of Radiologist. RCR CPD Scheme. 2020.

[14] General Medical Council. Continuing professional development. 2020.

[15] Liang ZC, Ooi SBS, Wang W. Pandemics and Their Impact on Medical Training: Lessons From Singapore. Acad Med. 2020 Sep; 95(9):1359-1361.

[16] Rose S. Medical Student Education in the Time of COVID-19. JAMA. 2020; 323(21): 2131-2132.

[17] Abdur Rahman Alfa Shaban. Ghana coronavirus: 29,672 cases; 100-bed specialist hospital ready. Africanews. 2020. https://www.africanews.com/2020/07/23/ghana-coronavirus-operational-guidelines-for-churchesmosques-issued// Accessed on 20th June, 2020.

[18] Säljö R. Materiality, learning, and cognitive practices: Artifacts as instruments of thinking. In T. Cerrato-Pargman \& I. Jahnke (Eds.), Emergent practices and material conditions in learning and teaching with technologies. 2012; 21-32.

[19] Liang ZC, Ooi SBS, Wang W. Pandemics and Their Impact on Medical Training: Lessons From Singapore. Acad Med. 2020; 95(9): 1359-1361.

[20] DePietro DM, Santucci SE, Harrison NE, Kiefer RM, Trerotola SO, Sudheendra D, Shamimi-Noori S. Medical student education during the COVID-19 pandemic: initial experiences implementing a virtual interventional radiology elective course. Academic Radiology. 2021 Jan 1; 28(1): 128-35.

[21] Bhattarai D, Sharma A, Sengupta P. Utility and perceptions about web-based academics among physicians during COVID-19 pandemic. J Family Med Prim Care. 2021; 10(2): 699-705. 
[22] Figueroa F, Figueroa D, Calvo-Mena R, Narvaez F, Medina N, Prieto J. Orthopedic surgery residents' perception of online education in their programs during the COVID-19 pandemic: should it be maintained after the crisis. Acta Orthopaedica. 12 Jun 2020: 1-4.

[23] Alsoufi A, Alsuyihili A, Msherghi A, Elhadi A, Atiyah H, Ashini A, et al. Impact of the COVID-19 pandemic on medical education: Medical students' knowledge, attitudes, and practices regarding electronic learning. PloS one. 25 Nov 2020; 15(11): e0242905.

[24] Wagner F, Knipfer C, Holzinger D, Ploder O, Nkenke E. Webinars for continuing education in oral and maxillofacial surgery: the Austrian experience. Journal of cranio-maxillofacial surgery. 1 Apr 2019; 47(4): 537-41.

[25] Webinar Training: an acceptable, feasible and effective approach for multi-site medical record abstraction: the BOWII experience. Avila CC, Quinn VP, Geiger AM, Kerby TJ, St Charles M, Clough-Gorr KM BMC Res Notes. 20 Oct 2011; 4: 430.

[26] Gegenfurtner A, Ebner C. Webinars in higher education and professional training: a meta-analysis and systematic review of randomized controlled trials. Educational Research Review. 1 Nov 2019; 28: 100293.

[27] Khajuria A. Evaluating the usefulness and utility of a webinar as a platform to educate students on a UK clinical academic programme. JR Coll Physicians Edinb. 2019; 49: 317-22.

[28] Kimura S, Onishi H, Kawamata M. Characteristics and perceptions of twice-weekly webinars for primary care physicians in Japan: a qualitative study. Int J Med Educ. 31 Aug 2018; 9: 229-238.

[29] Hilal K, Faruqui Z, Din NU, Memon MA, Siddique U, Khurshid K. Webinars for continuous medical education during covid-19: a cross-sectional survey of attendees' perspectives. PJR. 29 Jun 2021; 31(2).

[30] Ismail II, Abdelkarim A, Al-Hashel JY. Physicians' attitude towards webinars and online education amid COVID19 pandemic: When less is more. PloS one. 16 Apr 2021; 16(4): e0250241.

[31] Hoke AM, Francis EB, Hivner EA, Simpson AJL, Hogentogler RE, Kraschnewski JL. Investigating the effectiveness of webinars in the adoption of proven school wellness strategies. Health Educ J. 2018 Mar; 77(2): 249-257.

[32] Weston CM, Sciamanna CN, Nash DB. Evaluating online continuing medical education seminars: evidence for improving clinical practices. Am J Med Qual. 2008 Nov-Dec; 23(6): 475-83.

[33] Gupta R, Shah NT, Moriates C, Wallingford S, Arora VM. Disseminating innovations in teaching value-based care through an online learning network. J Grad Med Educ. 2017; 9: 509-13.

[34] Hari Prasetyono TO, Christian A Ann. Multiscreen to screen webinar for education beyond border: A review. Med Surg (Lond). 2020 Nov; 59: 237-241.

[35] Bell J, Mahmood S. Webinar popularity. Br Dent J. 2020; 228: 739.

[36] Patel NM, Khajuria A, Khajuria A Ann. Utility of a webinar to educate trainees on UK core surgical training (CST) selection - A cross sectional study and future implications amidst the COVID-19 pandemic. Med Surg (Lond). Nov 2020; 59: 35-40.

[37] Serebrakian AT, Ortiz R, Christensen JM, et al. Webinar during COVID-19 Improves Knowledge of Changes to the Plastic Surgery Residency Application Process. Plast Reconstr Surg Glob Open. 2020; 8(10): e3247. 